\title{
Eleventh Street
}

\section{Amiel Courtin-Wilson}

The thrift store manager wears female clothing when the lights go out and the magnets by the front counter are talismans - especially the beer mug las vegas magnet - that is a fucking grail - he won't sell it to me - there is excessive mucous in my face - $\mathrm{i}$ can't concentrate on him too long - i bend over and make a sound like an old man truth is like gristle and the meat on my plate has a long long shadow - the kettle boils over in the back room and the thrift store manager shouts at someone to turn it off - it's making a droning high pitched sound that sounds like a flatline - i tell him this - your kettle sounds like a flatline - he doesn't smile - he just says dourly - i know - i ask him again for the las vegas magnet - his eyelids flutter slightly and he pulls down the front of his top - he has a burn mark above his heart - it's either a burn mark or a scar of some sort - the kettle hasn't been turned off and the sound from the back of the thrift store seems 
louder - i close my eyes for a second and try to breathe but it feels as though someone is choking me and all the air in my stomach is expanding - $i$ ask him again if $i$ can have the las vegas magnet - he puts his finger against the scar above his heart and prods it with his unclean fingernail - clear liquid appears and quickly leaks down his chest - he isn't smiling but it doesn't seem to hurt him either - i ask him how he got the scar - he tells me he was born with it - $\mathrm{i}$ feel a surge in the floor and my shoes feel as though they might be melting and soldering themselves to the polished concrete - my face suddenly turns hot and $i$ breathe again - $i$ ask him if he has ever tried to see a doctor about what it might be? - he turns around and adjusts something on himself before facing me again and shaking his head - no doctor would know what to do with this - there is a dark rivulet forming in the middle of his malt liquor t-shirt where the wound has begun to leak - the rivulet looks as though it's lengthening like some kind of graph - it's happening so quickly - i ask him if he wants to sit down as he is sweating - he says no - $i$ ask him one final time for the las vegas magnet and he smiles - the flatline sound from the back of the thrift store intensifies - it reaches out for me and tries to tackle me to the ground - again i feel as though $i$ have to leave this place as quickly as possible - but i can't remember feeling that feeling before now - it has a golden light to it - this feeling - but the noise is so loud that maybe it's my eyes giving in to me - $i$ think about sonar and the importance of morse code in world war two - $i$ think about being stuck in a submarine - i feel like vomiting - $i$ can see myself vomiting all over the thrift store counter - all over the jewellery made from plastic and the purple charms and the board games with incomplete manuals and the isaac asimov books and the 
door opens to the thrift store and two policemen walk in with their guns hanging loosely from unclipped holsters - i can't turn around or move my feet so i smile at them but the smile comes out too big and they don't look happy and the wound from the transvestite's chest has begun to weep even more so i can see the outline of the transvestite's distended belly - his belly seems to be heaving independently of his breathing - as if he were pregnant - i look at the guns hanging loosely in their holsters and desperately want to touch them - $\mathrm{i}$ can feel my bowels loosening and blood seems to have filled my mouth - my saliva tastes like a chemistry test - the thrift store is underground or at least sinking - robert palmer is in the background and he is beckoning to me to shout all these observations aloud so i don't collapse under the weight of my mismapped thoughts - $i$ can see headlines written and rewritten in small offices with coffee and the telephone rings and the steam is piercing my heart and $i$ shit myself and the police officers yell something at me but $i$ can't understand them anymore - all $i$ can see is the river of fluid seeping from the wound on this transvestite's chest - the subway station is a block from here and if $i$ run now and don't hesitate then maybe $i$ can get a good head start and not knock over any peanut sellers on the way and think about the bed that i came from and not cry - as long as i don't start to cry - there is nothing wrong with a man who shits himself in a thrift store - it must be like second nature for this transvestite to clean up the remains of such an accident - so i tense my muscles and a murmur comes out that everyone seems to hear except me - $i$ have just said something but $i$ haven't understood what it is that $i$ have said - it must have been shocking somehow because i can feel hands on my shoulders and a handkerchief and tie stand 
Amiel Courtin-Wilson

on the counter falls in front of my face and through the thin silken material of the falling handkerchieves i can see the smiling face of the weeping transvestite and the vertical flatline that is flooding his belly and i make a wish - 